\title{
ELEMENTOS PRINCIPALES DE LA CRÍTICA DE HANS JONAS A LA MODERNIDAD ${ }^{1}$.
}

\begin{abstract}
Alberto Sánchez León
Abstract:

In his work The Phenomenon of Life: Toward a Philosophical Biology, Jonas contends that Modernity is unsustainable, or at least susceptible to a considerable correction. Such susceptibility is identifiable in the theory of knowledge, where a monopoly in epistemology has reduced all knowledge to immanent knowledge. Modern man's vision has been so impaired by the immanence of knowledge that he tends to deny any hint of transcendence.

Jonas sees the root of such immanence in the concept of perception and in the denial of causality, which are supported by the anti-anthropomorphism of those who have imposed the paradigm of modern knowledge and science.
\end{abstract}

Key words: Jonas, perception, causality, anthropomorphism and teleology

En su obra El principio vida. Hacia una biología filosófica, Jonas considera que la Modernidad es insostenible, o mejor, susceptible de una considerable corrección. El ámbito de tal susceptibilidad lo detecta en la teoría del conocimiento, pues considera que ha habido un monopolio en la epistemología que ha hecho que el único conocimiento posible sea el conocimiento inmanente. El enquistamiento del hombre moderno en la inmanencia del conocimiento lo ha cegado hasta tal punto que se tiende a negar todo atisbo de trascendencia.

La raíz de tal inmanencia la ve Jonas en el concepto de percepción y en la negación de la causalidad, que lo ampara el antiantropomorfismo propio de aquellos que impusieron el modelo de conocimiento y de ciencia moderna.

Palabras clave: Jonas, percepción, causalidad, antropomorfismo y teleología.

${ }^{1}$ Revista Mayéutica, ISSN 0210-2900, Vol. 38, № 85, 2012 , págs. 103-109. 


\section{Hegemonía de la percepción y pérdida de la causalidad como rasgo esencial de la Modernidad.}

Bien es sabido que para Hume una causación no es perceptible. La causación no se nos da entre los datos de la percepción. El empirismo humeano observa la percepción como mera receptividad que registra los datos que nos llegan por los sentidos.

Tanto para Hume como para Kant ${ }^{2}$ el único modo en que se nos da el mundo exterior es la percepción pasiva. Sabemos sólo por receptividad que es nuestra actividad propia corporal. A los contenidos que recibimos y guardamos: los interpretamos. Interpretamos secuencias de datos para poder verlos como acciones. Por tanto, la causalidad es un añadido mental a la materia prima de lo dado originariamente, que son impresiones subjetivas. Con otras palabras, la causalidad pasa a ser para el pensador de Königsberg una categoría, algo mental propio del sujeto.

En ambos pensadores hay una especie de pacto en llamar a la causalidad un añadido mental. Hume ve ese añadido en la costumbre de la asociación. Kant ve tal añadido en la estructuración obrada por el entendimiento (categorías). La diferencia de Hume y Kant es que mientras para el primero el añadido es algo pasivo por el sujeto, recae más en la imaginación; para el segundo, en cambio es activo, pero no transitivo, es decir, es el sujeto a través de la categoría de causalidad quien pone. En ambos se observa la hegemonía de la percepción y el consiguiente desplazo de la causación. Aunque, en el fondo, Kant es deudor de las premisas humeanas, pues piensa en la percepción como una sucesión de ideas neutrales, de representaciones o imágenes. Aún así, lo que se quiere recalcar es que el monopolio se hace bien patente: todo conocimiento es percepción, ya sea por un acto del sujeto, ya sea por una pasión (que le acontece, que recibe pasivamente) del mismo.

Con todo, tenemos que, respecto al concepto de causalidad, hay en Hume una coacción sentida por la imaginación, mientras que en Kant existe una necesidad comprendida procedente del entendimiento, ya sea bajo reglas psicológicas como por reglas racionales. Ambas posiciones aspiran a poner un dinamismo interno en el lugar de un dinamismo externo. Tal dinamismo lo pone Hume en la imaginación, y Kant en el entendimiento.

La primera conclusión que extrae Jonas es que la vivacidad de la impresión anímica no es un argumento, pues interpretar no es un argumentar. A esta injusta identificación de interpretar y argumentar Jonas la equipara a la retórica, pues el hecho de estar convencido de

\footnotetext{
${ }^{2}$ Yo añadiría también a Berkeley, para quien esse est percipi et percipere.
} 
algo no significa necesariamente estar en la verdad respecto a ese algo.

Si quitamos la causa porque ella no es perceptible (Hume) o porque es puesta por el sujeto (Kant), entonces entramos en la ignorancia más supina, pues, como decía Aristóteles, la ciencia es un saber cierto por causas. Por tanto, la relación epistemológica sujetoobjeto queda mermada porque no se sabe. Quitar la causa es, en definitiva, no saber. Si, como dice Millán-Puelles, "el saber y la ciencia son, en resolución, exactamente lo mismo", entonces la Modernidad es la puerta de entrada al agnosticismo y al escepticismo. Mermada la ciencia en su raíz, la verdad se pone en juego y, por tanto, todo es interpretable ${ }^{4}$, también ese todo, como afina Nietzsche.

Hurtar la causa es despojar la naturaleza del hombre, pues "todo hombre desea por naturaleza saber", . El hombre moderno quiere explicar al hombre sin el hombre, porque una vez que quita el saber, la causalidad, entonces sólo cabe suponer. Quien quita lo necesario, de alguna manera lo pone, o mejor, lo supone. Este ha sido, en gran parte, el inicio de la era Moderna: la suposición de todo lo necesario para "explicar" lo necesario. Pero suponer requiere, de algún modo fe. Y esta es la gran paradoja: la modernidad como paradigma de la racionalidad no hace más que usar la fe como inicio de todo su sistema, una fe, claro está, reducida a poner lo que no puedo explicar, un fideísmo no sólo de lo trascendente, sino también del propio hombre y del mundo.

Con ello, el dualismo con hegemonía del sujeto del binomio esencial sujeto-objeto se postula como principal y axiomático, porque el sujeto es el que percibe. De este modo, todo queda encerrado en la subjetividad, en la conciencia, y por tanto no cabe hablar de autotrascendencia del yo en la acción.

Ahora bien, Jonas hace notar que tal enclaustramiento en el sujeto acaba en un necesario solipsismo. Sin embargo, como el solipsismo es insostenible por cualquier pensador razonable, la conclusión que sacamos es que la negación de la causación nunca ha sido seria ni razonable, tanto por Hume como por Kant.

Podría parecer que tanto Hume como Kant aceptan la mudez causal de lo percibido.

En Hume, este hacer desaparecer su propio carácter causal constituye un rasgo esencial de la inmediatez presentativa (en palabras de Whitehead) y es la condición de la función objetiva de ésta última.

Para Whitehead hay dos tipos de percepción que son complementarias: la eficiencia causal y la inmediatez presentativa.

\footnotetext{
${ }^{3}$ Millán-Puelles, A., Léxico filosófico, Rialp, Madrid, 1984, p. 127.

${ }^{4}$ Es interesante observar que es en la Modernidad donde irrumpe también el protestantismo, cuyo papel principal es la interpretación de las Escrituras. Se interpreta el dogma, se interpreta la verdad, se juega con ella, y, la verdad del hombre se oscurece. Y, de la hermenéutica al relativismo el trecho es bastante estrecho.

${ }^{5}$ ARISTÓTELES, Metafísica, lib. 1, cap. 1.
} 
Esta distinción supone una contribución a la solución del problema de Hume, pero no da una explicación suficiente de sí misma ${ }^{6}$.

Con la distinción que hace Whitehead, Jonas se propone solucionar, y a mi juicio aquí está el meollo de su atinada crítica a la Modernidad, las siguientes aporías:

a) ¿Cómo es que los sentidos difuminan las huellas de su propia constitución causal al integrar su propio producto representativo? ¿Cómo logran los sentidos darnos un contenido descausalizado?

b) ¿Por qué la exclusión del elemento causal se extiende desde el autotestimonio del proceso perceptivo actual a su imagen objetual general, es decir, llegando a abarcar la esfera de la objetividad como tal, que de esta manera es realidad (desactivada) desnaturalizada, pero que de otro modo no sería posible? (Porque la percepción objetiva lo que hace es objetivar objetos desactivados o desnaturalizados).

c) ¿Por qué los modos objetivantes de relación con el mundo así constituidos han tenido que monopolizar el concepto de conocimiento, y los objetos de ese tipo el de realidad, debido a lo cual se han generado ciertos problemas que son peculiares de esta selección de las fuentes del saber? (El modo de conocer es por percepción y así la ciencia usa este método rechazando la noción de causa. De nuevo sale la famosa sentencia Ser es percibir o lo percibido, como imponía Berkeley).

El resultado al que llega Hume al igual que Kant aunque por distintos caminos "no es más que lo que cabía esperar de la naturaleza y del sentido propios de la percepción; que con esta confirmación ese resultado queda restringido simultáneamente al campo al que pertenece, y por ello despojado de sus consecuencias escépticas; que lo más necesitado de explicación no es cómo pasamos del vacío causal de la percepción a la idea de causa, sino cómo es que precisamente la percepción no la muestra, es decir, logra ocultarla, de manera que lo asombroso es su ausencia en la percepción y no su presencia en nuestras ideas; que el aspecto primario de la causalidad no es la conexión regular, ni siquiera la conexión necesaria, sino la fuerza y la producción de efectos; que la fuerza y la producción de efectos son contenidos originarios de la experiencia y no interpolaciones entre contenidos de experiencia (percepciones) realizadas por una función sintética, sea ésta última la asociación o el entendimiento; que, de hecho, la fuente de esta experiencia no es la percepción sensible, sino nuestro cuerpo en el esfuerzo de la acción, precisamente aquella fuente que Hume descalificó sumariamente bajo el rótulo de «conato animal»; finalmente, que el derecho a extrapolar esta fuente yendo más allá de la esfera inmediata en que comparece es una cuestión que una filosofía orgánica debe estudiar sin temor alguno al reproche de que al hacerlo incurre en antropomorfismo"

\footnotetext{
${ }^{6}$ Cf., Jonas, H., El principio vida, Trotta, Madrid 2000, p. 47.

${ }^{7}$ JONAS, H., El principio vida, p. 53.
} 


\section{Antropomorfismo y teleología}

Forma parte del credo de la ciencia moderna, dice Jonas, la devaluación de las causas finales. Y es que, cuando la ciencia se ocupa de la teleología se limita a rechazar su forma antropomórfica de un universo configurado para la utilidad del hombre, como pensarán los anti-antropomorfos. Pero ¿cabe otra visión fuera del hombre? ¿Es el antropomorfismo un determinismo de nuestro modo de proceder y de habérnoslas con las cosas o la propia condición del hombre? ¿Qué le queda, qué enfoque posee el antropomorfista si no es un enfoque humano? "En toda tabla de los mandamientos y prohibiciones que el credo científico como tal lleva consigo, entre las prohibiciones debe ocupar el primer lugar el de la teleología, esto es, la prohibición de las causas finales?"

Sin embargo, la exclusión de la teleología, que es el modo de ser propio de la naturaleza misma como afirma Jonas 9 no es un resultado inductivo de la ciencia moderna, sino un decreto apriorístico de la misma.

Prácticamente los hechos mismos se consideran probados y no necesitados de argumentos a su favor. Pero las causas finales pertenecen a la naturaleza del hombre y no a la del universo, lo que supone que son diferentes seres ${ }^{10}$.

Sin causas finales como método de la ciencia, la investigación queda dirigida por sus resultados $\operatorname{mismos}{ }^{11}$. Y, si es dirigida no interesa la verdad. La verdad queda excluida en pro del progreso, y este como camino o medio de una sociedad del bienestar. Son muy tajantes las palabras de Guardini respecto al progreso como fin propio de la Modernidad: La Edad Moderna gustaba de justificar las medidas de la técnica por su utilidad para el bienestar del hombre. Así encubría los estragos que ocasionaba la falta de escrúpulos de la misma (...). El hombre que posee la técnica sabe que, en el fondo, ésta no se dirige ni a la utilidad ni al bienestar, sino al dominio; el dominio, en el sentido más extremo de la palabra, y que está hallando su expresión en una nueva estructura del mundo. El hombre intenta controlar tanto los elementos de la naturaleza como los de la existencia humana"12.

Todo esto lo explica Jonas cuando pone el inicio de la Era Moderna justamente en la separación cartesiana de la res cogitans y la res extensa. El resultado de esto es el monopolio epistemológico, y la única herramienta la percepción.

\footnotetext{
${ }^{8}$ Ibíd.

${ }^{9}$ Cf., Ibid, p. 54.

${ }^{10}$ Cf., Ibíd., p. 65.

${ }^{11}$ Es curioso también observar que también la ética moderna se deja llevar por los resultados de la acción, imponiéndose también la ética consecuencialista, como, por ejemplo, la misma ética kantiana.

${ }^{12}$ GUARDInI, R., El ocaso de la Edad Moderna, ediciones Guadarrama, Madrid 1958, pp. 83-84.
} 
La objetividad se convierte esencialmente en el resultado de la elaboración a que se someten los datos de los sentidos externos en atención a sus propiedades extensionales. Por tanto el conocimiento es construcción. Aquí se ve la matriz del idealismo.

El antropomorfismo y también el zoomorfismo se convirtieron en alta traición científica. La naturaleza del hombre se considera fuente de impureza para la filosofía precisamente porque es teleológica.

Spaemann, gran conocedor del pensamientote Jonas, también defiende el antropomorfismo frente al antropocentrismo moderno, pues mientras que uno es la condición del ser humano y su finalidad es conocer la verdad de las cosas; el otro, tergiversa el orden del conocimiento y ya no se ocupa como principal tarea de la verdad sino del control. "La alternativa al tan denostado antropomorfismo en Biología es el antropocentrismo. El mundo moderno es, como ningún otro con anterioridad, antropocéntrico. Tampoco la nueva sensibilidad medioambiental cambia en nada esta característica. Por el contrario, todo lo existente no humano se define como medio ambiente, como contexto para el hombre. La protección de las especies tiene que ver algo con la conciencia ecológica porque las especies naturales pertenecen a la riqueza de nuestro mundo. Sin embargo, la protección de los animales no tiene que ver en el fondo con nada de esto, ya que sólo está referida a los animales. La ciencia moderna es antropocéntrica. Ella no se cuestiona lo que es realmente y por qué razón posee el carácter de la coexistencia (Mitsein) con nosotros, sino cómo se nos da como objeto y en qué medida podemos manipularlo. Conocer una cosa quiere decir - tal como lo escribió uno de los padres del pensamiento antropocéntrico de la ciencia moderna, Thomas Hobbes«saber lo que puedo hacer con ella cuando la poseo». Para saber lo que puedo hacer con una cosa no necesito conocer lo que realmente es ella misma. Por tanto, podemos renunciar al antropomorfismo a favor del antropocentrismo. En cuanto son objetos puros, las cosas están frente al sujeto y no tienen nada en común con él. Querer comprender la realidad como tal significa contemplarla desde el punto de vista de su mayor o menor parecido con nosotros. La ciencia puede objetivar bien el comportamiento de los elementos más simples de la materia inerte, lo que está más alejado de nosotros. E intenta comprender lo más próximo a nosotros, y a nosotros mismos, como combinación compleja de esos elementos. Cuanto más compleja, más difícil resulta esa comprensión. Que tal combinación pueda dar como resultado un cuarteto de cuerda de Beethoven, o las fórmulas de la teoría de la relatividad, es algo que permanece en una oscuridad impenetrable. Si no tratamos de objetividades, sino que queremos comprender la realidad, entonces la cuestión se presenta a la inversa: comprendemos el cuarteto de cuerda o la teoría de la relatividad mejor incluso que la bacteria, en caso de que exista en cualquier forma. Si ello no fuera posible, entonces ya no podríamos comprender nada más, sino solamente registrar datos objetivos" 13 .

Para el pensador moderno, la lucha contra la teleología es una lucha contra el antropomorfismo. Ya hemos visto que la crítica a la causalidad no es seria, pero ahora vemos también que renunciar al antropomorfismo es, en definitiva, renunciar al hombre. Esta ha sido

${ }^{13}$ Spaemann, R., Ética, política y cristianismo, Palabra, Madrid 2007, pp. 198-200. 
la deriva de la modernidad: la deconstrucción de lo que el hombre es. Por eso, Heidegger no quiere hacer de ningún modo antropología, sino ontología fundamental, pues no quiere caer en el antropomorfismo. Con Sein und Zeit Heidegger quiere rescatar la pregunta sobre el ser en general, quiere darle un realce metafísico a su propuesta porque no quiere caer en un antropologismo. Su pregunta no es antropológica. Sospecho en este no enfrentarse al problema del hombre un antiantropomorfismo heideggeriano, fruto del conformismo que hace Heidegger de la filosofía moderna. En este sentido Heidegger es, a mi juicio, el culmen de la modernidad e incoa una postmodernidad que también nace de los elementos visto en este trabajo. Jonas es más inconformista que su maestro.

Una vez rechazada la explicación (porque explicar es dar razones, es ir a la causa, es, en definitiva, saber) se da paso a la descripción (descripción matemática) ${ }^{14}$. Se evapora la noción misma de "explicación" con el movimiento anti-antropomórfico de la teoría del conocimiento. Y de aquí se pasa a la renuncia agnóstica, a la idea de saber como comprensión de sus objetos (No se tiene en cuenta la idea de Dilthey que recoge como trasfondo la noción de los conceptos de explicación-comprensión como una posible recuperación del sentido en la comprensión, de la unidad del todo propio de las ciencias del espíritu, frente al atomismo causal que requiere la explicación como lo propio de las ciencias).

El finalismo debe tener su sede legítima en aquel lugar del que pudo ser derivada su idea, y en la división dualista todavía no está negada la naturaleza del hombre o de la vida que proporciona esa sede, sino que está meramente disociada de la res extensa. Sin finalismo se admite una metafísica dualista.

Jonas nos deja una tarea no menor para nuestro tiempo que se cifra en la reapertura postdualista de la pregunta, o, más bien, de la alternativa a raíz de su crítica a la filosofía moderna.

A) Entender la presencia de interioridad dirigida a fines en una parte del orden físico, a saber, en el hombre, como un testimonio válido de la naturaleza de aquella realidad ulterior que esa interioridad hace surgir de sí misma, y aceptar lo que ella revela en sí misma como parte de la evidencia universal.

B) Extender las normas de la materia mecánica hasta el corazón de la clase de fenómenos aparentemente heterogéneos y desterrar a la teleología incluso de la naturaleza del hombre.

Alberto Sánchez León asanleo@gmail.com

${ }^{14}$ Cf., Jonas, H., El principio vida, p. 57. 